\title{
HISTORICAL REMARKS
}

\section{Suzanne Débarbat \\ Observatoire de Paris}

As president of Commission 41 of the IAU (History of Astronomy) I would say a few words about Astronomy in China which is indeed a very long tradition.

May I remind you that the compass for travellers was used in China as early as before the begining of the Christian era and that the terrestrial magnetic field was known in China one millenium later, that is to say about half of this time before the Europeans. These facts are in the field of geophysics ; closer to astronomy, and used both for astrometry and for astrophysics, is the equatorial mounting which is said dating from the 13th century in China. And we must not forget the old records about novae, comets and sunspots and, for the special case of astrometry and its impacts, those of old eclipses which have given informations about the rotation of the Earth.

As a french astronomer I would say also a few words on the occasions we are celebrating : the one hundred and twenty years of the creation of an Observatory in Shanghaï, the 70th anniversary of the foundation of the Chinese Astronomical Society and the 30th Anniversary of the modern Shanghai Observatory the one we know nowadays ; that would be made through some relationships between China and France, which are now historical examples.

May I remind you that after the creation of the IAU, China entered it in 1935, the year the General Assembly was held in Paris. Among the members, a certain $\mathrm{Li}$ Heng (or $\mathrm{Li} \mathrm{Hen}$ as written in France) from Kunming in the Yunnan. He was formely a student, born in 1898, arrived at the Paris Observatory in 1931 where he worked at the Carte du Ciel service under the direction of Henri Mineur. The field of research was, among others, clusters and in $1932 \mathrm{Li}$ Hen made a determination of the "zero" of the period-luminosity diagram for the Cepheïdes and performed another research on their space distribution and their velocities.

The following year, and besides some works at the meridian circle of the Paris Observatory, Li Hen pursued his stellar researches. So well done that on July the 5th, in 1933, he submitted a thesis at the Sorbonne (the Paris University) under the french title "Recherches statistiques sur les Cepheïdes" which could be simply translated in English "Statistical Research on the Cepheids". The Jury was composed of Ernest Esclangon, then director of the Paris Observatory and professor of astronomy at the Sorbonne. Jean Chazy, professor of celestial mechanics and Armand Lambert, head of the services of the Bureau International de l'Heure. Mineur had to report on $\mathrm{Li}$ Hen's work ; the end of his report noticed the scientific qualities of $\mathrm{Li} \mathrm{Hen}$, the high level of results he obtained in this field of astronomy. The memoir contains 132 pages and the second proposal by the Faculty of Sciences in the Sorbonne is entitled "Equations canoniques d'Hamilton" showing that $\mathrm{Li} \mathrm{Hen}$ was also studying more theoretical subjects.

We have seen that, back in his home country, Li Hen was one of its representive in 1935 in Paris. The Second World War (1940-1945) separated Li Hen 
and Mineur. Li Hen in China came to Shanghaï in the fifties. He became the first director of the modern Shanghaï Observatory, in 1962, at its creation. Li Hen has been the teacher of astronomy of several participants of the present IAU Symposium and, among them, the president of the Local Organizing Committtee, Prof. Miaofu $\mathrm{He}$ from Shanghaï Observatory. And of course nowadays Prof. Mrs Shuhua $\mathrm{Ye}$ is his successor as director of the Shanghaï Observatory.

Li Hen died in 1989 being, at that time, honorary director of the Shanghai Observatory. Li Hen was a man of great power at work. His scientific activity is associated to a permanent action to improve the knowledge of science, particularly through the translations he made, from French to Chinese, for several major books. Such was the case of Astrophysique générale from Pecker and Schatzman, Exposition du Système $d u$ monde from Laplace. Astronomie générale from Danjon, traductions which appeared, respectively, in 1964, 1978 and 1980 ; at this last date he had more than 80 years...

The works Li Hen has made at the Paris Observatory were very important mostly for impacts on astrophysics. The researches was pursed in France by Mineur who became a specialist of the Cepheids during the hard time of the Second World war. In 1944 he established that the "zero" of the period-luminosity diagram of the Cepheids had to be changed because the distance of these objects had been under-estimated. The result, independantly found by Baade eight years later in 1952, brings to increase by a factor two the distances in the Universe. By an astrometric measurement the conceptual idea of the Universe was changed and both China and France were associated in the work which began in the thirties.

May I also mention another chinese astronomer as an historical example of relationship between France and China. His name is Zhen Mao-Laing, (Tcheng Mao Lin in France). One can find, as soon as during the Second World War, papers he published wian ine was working at the Lyons Observatory of which Jean Dufay was director. Their fields of research were the spectrophotometry of stars and the light of the sky at night. Most of the papers published during the following years are in the Comptes rendus de l'Académie des sciences, in the Annales de Géophysique, in the Annales d'Astrophysique. They are published sometimes with Dufay, but also with young astronomers of the time, observing at the HauteProvence Observatory and named Marie Bloch or Charles Fehrenbach.

After the war Tcheng Mao Lin pursued his work at Lyons Observatory until his departure to return to China in 1957. He was a member of the IAU from 1952 and at the time of the IAU General Assembly in Moscow (1958) he was in Beijing. I met him during the French National Committee for Astronomy Meetings in the mid-fifties being arrived myself at the Paris Observatory in 1953; I met him also on March 26 in 1966 when he came to Paris. By the end of his carrier he had a proeminent position in China about the astronomical research. In the seventies. old and rather sick, he received a team of the French TV in China, for astronomical purposes, and he was happy when remembering his french colleagues. Tcheng Mao Lin died on the 31st of December in 1978.

I will not speak about the following cooperation between China and France because it is too recent and also in the field of astrometry, specially well known both in Paris and in Shanghaï. This cooperation and the international cooperation of the present time are topics for future historians of science. It will be also a topic for the coming century to speak about the IAU Symposium $\mathrm{n}^{\circ} 156$. Let me wish that, on the occasion of the next celebration anniversaries there will be some people to give rememberances of the present meeting and its achievements. 